\title{
Pro-inflammatory cytokines and oxidative stress/antioxidant parameters characterize the bio-humoral profile of early cachexia in lung cancer patients
}

\author{
NICOLETTA FORTUNATI ${ }^{1}$, ROBERTA MANTI $^{1}$, NADIA BIROCCO $^{2}$, MARIATERESA PUGLIESE $^{1}$, \\ ENRICO BRIGNARDELLO ${ }^{1}$, LIBERO CIUFFREDA ${ }^{2}$, MARIA G. CATALANO ${ }^{3}$, \\ MANUELA ARAGNO ${ }^{4}$ and GIUSEPPE BOCCUZZI ${ }^{1,3}$ \\ ${ }^{1}$ Oncological Endocrinology and ${ }^{2}$ Medical Oncology, ASO San Giovanni Battista, Corso \\ Bramante 88, Turin; ${ }^{3}$ Department of Clinical Pathophysiology, University of Turin, Via Genova 3, Turin; \\ ${ }^{4}$ Department of Experimental Medicine and Oncology, University of Turin, Corso Raffaello 30, Turin, Italy
}

Received March 8, 2007; Accepted June 25, 2007

\begin{abstract}
Cancer-related cachexia, that is present in about 50\% of cancer patients and accounts for $20 \%$ of all cancer deaths, is clinically characterized by progressive weight loss, anorexia, metabolic alterations, asthenia, depletion of lipid stores and severe loss of skeletal muscle proteins. The main biochemical and molecular alterations that are responsible for the syndrome are prematurely present in the progress of the disease and the identification of the early stages of cachexia can be useful in targetting patients who will benefit from early treatment. The aim of the present study was to delineate the bio-humoral profile of a group of lung cancer patients either non-cachectic or cachectic by evaluating serum proinflammatory cytokines and oxidative stress/antioxidant parameters (both recognized to be involved in cachexia pathogenesis) and pro-inflammatory cytokine gene expression in PBMC (Peripheral blood mononuclear cells) of cancer patients. All serum pro-inflammatory cytokines and oxidative stress/antioxidant parameters significantly increased in neoplastic patients, but only TNF- $\alpha$, ROS, GSH and vitamin E showed a significantly greater increase in cachectic patients. Pro-inflammatory cytokine gene expression mirrored serum level behaviour except for IL-6 that was increased in serum but not as gene expression, suggesting its provenience from tumour tissue. Our data support that the simultaneous determination of ROS, GSH, vitamin E, together with TNF- $\alpha$ allows the identification of a lung cancer patient developing cancer-related cachexia. This bio-humoral profile should be used for the early diagnosis and follow-up of the syndrome. Moreover, the evaluation of gene expression in patient PBMC was helpful in differentiating tumour vs host factors, therefore
\end{abstract}

Correspondence to: Professor Giuseppe Boccuzzi, Department of Clinical Pathophysiology, Via Genova 3, 10126 Turin, Italy

E-mail: giuseppe.boccuzzi@unito.it

Key words: lung cancer, cachexia, cytokines, oxidative stress being useful in the study of pathogenetic mechanisms in neoplastic cachectic patients.

\section{Introduction}

Cancer-related cachexia is a life-threatening paraneoplastic syndrome present in about $50 \%$ of cancer patients. It is clinically characterized by progressive weight loss, anorexia, metabolic alterations, asthenia, depletion of lipid stores and severe loss of skeletal muscle proteins and accounts for $\sim 20 \%$ of all cancer deaths $(1,2)$. Its prevalence is higher in patients with tumour of the gastrointestinal tract and the lung, than in those with other solid or haematologic malignancies (3). The pathogenesis of cancer-related cachexia is still not fully understood, even though several different pathways and catabolic mediators (humoral and tumoural) have been recognized (4-6).

Since cachexia is present in most terminally ill cancer patients, it has long been considered a very late and ineluctable event in the natural history of the neoplastic disease. Many of the biochemical and molecular alterations that are thought to be responsible for the syndrome are already present prematurely in the disease progress and therefore, cancerrelated cachexia should be considered as an 'earlyphenomenon' $(7,8)$. Furthermore, soon after the diagnosis of cancer takes place, the troublesome and long therapy pathway the patient has to follow will increase factors leading to muscle wasting and cachexia (9). Unfortunately, the currently available therapeutic tools for cancer-related cachexia have offered only partial results, mainly because the intervention is very late and the development of an early and more effective intervention is sought (3).

In addition to the effort to look for a new therapy and different treatment timing, the identification of biological markers able to identify which patients to treat and when to treat them as well as to monitor treatment outcome is of increasing importance.

Proinflammatory cytokines, mainly TNF- $\alpha$, IL-6 and IL1ß, are recognized to be involved in the pathogenesis of cancer- 
related cachexia $(5,10)$. The serum levels of IL-6 were reported to be elevated in many patients with cancer and cancer-related cachexia but results for other cytokines and their relationship with the severity of clinical status are still discrepant (11-17). Reactive oxygen species and related oxidative stress markers are associated with muscle wasting in animals $(18,19)$ and have also been demonstrated to be altered in cachectic patients making them useful markers in monitoring the response to antioxidant treatment $(20,21)$.

Nevertheless, a precise bio-humoral profile able to identify the very first development of cachexia in order to target patients who will benefit from early treatment is still lacking. The aim of this study is to evaluate a panel of serum proinflammatory cytokines and oxidative stress parameters in order to delineate a useful bio-humoral profile able to detect the development of the disease at an early stage. Since in the tumours of the gastrointestinal cachexia seems to be influenced early by the site of the tumour, we enrolled only patients with lung cancer, that present cancer-related cachexia with a significantly high prevalence. Moreover, because it was reported that host response to cancer-related cachexia development is not always mirrored by serum cytokine levels (22), which cannot be used to discriminate between tumour versus host production, we also decided to evaluate cytokine gene expression on peripheral blood mononuclear cells.

\section{Materials and methods}

Patients. The study was conducted on 33 patients (mean age 65.0 years, range $54-75$ years; $\mathrm{M} / \mathrm{F}$ ratio $30 / 3$ ) with recently diagnosed lung cancer. Patients were not affected by any other serious disease (e.g. diabetes, liver cirrosis, heart, renal or pulmonary failure) and were not receiving any antineoplastic treatment or any treatment interfering with cytokine production (e.g. steroidal drugs, somatostatin analogues, nonsteroidal anti-inflammatory drugs) at the time of the study. All patients were referred to the S.C. Medical Oncology, ASO San Giovanni Battista, Torino. Written informed consent was obtained from all patients.

Samples of peripheral blood and serum were collected from each patient right after diagnosis, at 8:00 a.m. For each patient the following data were also obtained: tumour histology, stage of disease, performance status (ECOG), height $(\mathrm{cm})$, weight $(\mathrm{kg})$, BMI (body mass index). Patients were divided into two groups on the basis of a weight loss $>5 \%$ of initial weight in the six months preceding the study (weight loss $>5 \%$, cachectic patients, $n=14$; weight loss $<5 \%$, noncachectic patients, $n=19)$. Clinical characteristics of patients are reported in Table I. Peripheral blood and serum samples from 23 age-sex-matched normal subjects were used as controls.

Evaluation of serum IL-6, TNF- $\alpha$, sTNF-RI and sTNF-RII. Serum levels of IL-6, TNF- $\alpha$ and both its soluble receptors (sTNF-RI and sTNF-RII) were measured with a highsensitivity double-antibody ELISA test (Quantikine HS, R\&D System Inc., Minneapolis MN, USA), performed according to the manufacturer's instructions. Intra-assay variations were $7.1 \%$ for IL-6; $6.5 \%$ for TNF- $\alpha ; 2.5 \%$ for TNF-RI and $5.1 \%$ for TNF-RII; inter-assay variations were $9.9 \%$ for IL-6;
Table I. Clinical characteristics of lung cancer patients $(n=33)$.

\begin{tabular}{lrr}
\hline & $\mathrm{N}$ & $\%$ \\
\hline Lung cancer histology & & \\
Non-small cell & 23 & 70 \\
Small cell & 3 & 9 \\
Adenocarcinoma & 7 & 21 \\
Disease stage & & \\
IIIB & 14 & 42 \\
IV & 19 & 58 \\
ECOG & & \\
0 & 6 & 18 \\
1 & 19 & 58 \\
2 & 6 & 18 \\
3 & 2 & 6 \\
4 & 0 & 0 \\
BMI & & \\
$<18.5$ & 4 & 12 \\
$19-20$ & 4 & 12 \\
$21-25$ & 13 & 40 \\
$26-29$ & 10 & 30 \\
$>30$ & 2 & 6 \\
\hline
\end{tabular}

$10.2 \%$ for TNF- $\alpha ; 9.3 \%$ for TNF-RI and $7.1 \%$ for TNF-RII. Results are expressed in $\mathrm{pg} / \mathrm{ml}$.

Expression of IL-6, IL-6R, TNF-a, TNF-RI and TNF-RII genes

RNA extraction from peripheral blood mononuclear cells (PBMC). PBMC were separated on a Fycoll-Hypaque density gradient (Lymphoprep ${ }^{\mathrm{TM}}$, Axis-Shield PoC AS, Oslo, Norway), starting from $14.0 \mathrm{ml}$ of peripheral heparinized blood. After separation, cells were thoroughly washed with ice-cold saline and frozen at $-80^{\circ} \mathrm{C}$ until the experiment. Total RNA was extracted from PBMC with the Trizol reagent (Invitrogen, Groningen, The Netherlands) following the method developed by Chomczynski and Sacchi (23).

$R T$-PCR for gene expression evaluation. Total RNA was reverse-transcribed at $42^{\circ} \mathrm{C}$ for $40 \mathrm{~min}$ using AMV reverse transcriptase (Finnzymes, Finland) and oligodT primer (Invitrogen). The PCR reaction system contained $5 \mu 1$ of 10X PCR buffer, $10 \mu 1$ of RT product, $0.2 \mathrm{mM}$ dNTP (Finnzymes), 1.25U Taq DNA polymerase (Finnzymes), $50 \mathrm{ng}$ each of sense and antisense primers in a total volume of $50 \mu 1$. Primer sequences are reported in Table II. Amplification was carried out as follows; for TNF- $\alpha$ : $1 \times 95^{\circ} \mathrm{C}$ for $3 \mathrm{~min}$; $35 \mathrm{x}$ $94^{\circ} \mathrm{C}$ for $1 \mathrm{~min}, 58^{\circ} \mathrm{C}$ for $1 \mathrm{~min}$ and $72^{\circ} \mathrm{C}$ for $1 \mathrm{~min}$; and $1 \mathrm{x}$ $72^{\circ} \mathrm{C}$ for $7 \mathrm{~min}$; for IL-6: $27 \times 94^{\circ} \mathrm{C}$ for $40 \mathrm{sec}, 65^{\circ} \mathrm{C}$ for $40 \mathrm{sec}$ and $72^{\circ} \mathrm{C}$ for $40 \mathrm{sec} ; 10 \times 94^{\circ} \mathrm{C}$ for $40 \mathrm{sec} ; 56^{\circ} \mathrm{C}$ for $40 \mathrm{sec}$; $72^{\circ} \mathrm{C}$ for $40 \mathrm{sec}$; and $1 \times\left(72^{\circ} \mathrm{C}\right.$ for $\left.7 \mathrm{~min}\right)$; for TNF-RI: $1 \mathrm{x}$ $94^{\circ} \mathrm{C}$ for $3 \mathrm{~min} ; 35 \times 94^{\circ} \mathrm{C}$ for $30 \mathrm{sec}, 52^{\circ} \mathrm{C}$ for $1 \mathrm{~min}$ and $72^{\circ} \mathrm{C}$ for $1 \mathrm{~min}$; and $1 \times 72^{\circ} \mathrm{C}$ for $7 \mathrm{~min}$; for TNF-RII: $1 \times 94^{\circ} \mathrm{C}$ for $3 \mathrm{~min} ; 35 \times 94^{\circ} \mathrm{C}$ for $30 \mathrm{sec}, 60^{\circ} \mathrm{C}$ for $30 \mathrm{sec}$ and $72^{\circ} \mathrm{C}$ for $30 \mathrm{sec}$ and $1 \times 72^{\circ} \mathrm{C}$ for $7 \mathrm{~min}$; for B-actin: $1 \times 94^{\circ} \mathrm{C}$ for $3 \mathrm{~min}$; $35 \times 94^{\circ} \mathrm{C}$ for $30 \mathrm{sec}, 58^{\circ} \mathrm{C}$ for $30 \mathrm{sec}$ and $72^{\circ} \mathrm{C}$ for $30 \mathrm{sec}$ and $1 \times 72^{\circ} \mathrm{C}$ for $7 \mathrm{~min}$. PCR products were electrophoresed 
Table II. Serum concentration of pro-inflammatory cytokines in lung cancer patients.

\begin{tabular}{|c|c|c|c|c|}
\hline & $\begin{array}{l}\text { Controls } \\
\text { (ctrl) }\end{array}$ & $\begin{array}{l}\text { Non-cachectic } \\
\text { patients (nc) }\end{array}$ & $\begin{array}{c}\text { Cachectic } \\
\text { patients (c) }\end{array}$ & \\
\hline $\mathrm{TNF} \alpha(\mathrm{pg} / \mathrm{ml})$ & $1.887 \pm 0.26(n=14)$ & $2.646 \pm 0.53(n=17)$ & $4.182 \pm 0.6(n=13)$ & $\begin{array}{l}\text { ctrl vs nc, } \mathrm{P}<0.05 \\
\text { ctrl vs } \mathrm{c}, \mathrm{P}<0.01 \\
\text { nc vs c, } \mathrm{P}<0.05\end{array}$ \\
\hline TNF-RI (pg/ml) & $1024 \pm 90(n=15)$ & $1661 \pm 159(n=17)$ & $1573 \pm 68(n=13)$ & $\begin{array}{l}\text { ctrl vs nc, } \mathrm{P}<0.001 \\
\text { ctrl vs c, } \mathrm{P}<0.001 \\
\text { nc vs c, ns }\end{array}$ \\
\hline TNF-RII (pg/ml) & $1834 \pm 150(n=15)$ & $2449 \pm 181(\mathrm{n}=17)$ & $2996 \pm 286(n=13)$ & $\begin{array}{l}\text { ctrl vs nc, } \mathrm{P}<0.05 \\
\text { ctrl vs c, } \mathrm{P}<0.001 \\
\text { nc vs } \mathrm{c}, \mathrm{ns}\end{array}$ \\
\hline IL-6 (pg/ml) & $0.438 \pm 0.102(n=13)$ & $8.186 \pm 1.77(n=17)$ & $11.61 \pm 1.56(n=13)$ & $\begin{array}{l}\text { ntrl vs nc, } \mathrm{P}<0.001 \\
\text { ctlr vs c, } \mathrm{P}<0.001 \\
\text { nc vs c, ns }\end{array}$ \\
\hline
\end{tabular}

on $1.5 \%$ agarose gel in the presence of ethidium bromide. Gels were analyzed with the PC program Kodak 1D Image System. The net intensity of bands in each experiment was normalized for the intensity of the corresponding $\beta$-actin band.

\section{Evaluation of serum oxidative stress and anti-oxidant parameters}

Nitrite/nitrate. The nitrite/nitrate concentration in serum was used as an indicator of nitric oxide synthesis. Nitrates in serum samples were stoichiometrically reduced to nitrites by incubation of $250 \mu \mathrm{l}$ of the sample for $15 \mathrm{~min}$ at $37^{\circ} \mathrm{C}$, in the presence of $1 \mathrm{IU} / \mathrm{ml}$ nitrate reductase, $500 \mu \mathrm{M}$ NADPH and $50 \mu \mathrm{M}$ FAD in a final volume of $400 \mu 1$. When nitrate reduction was complete, unused NADPH, which interferes with subsequent nitrite determination, was oxidized by $100 \mathrm{IU} / \mathrm{ml}$ lactate dehydrogenase and $100 \mathrm{mM}$ sodium pyruvate in a final reaction volume of $500 \mu 1$ and incubated for $5 \mathrm{~min}$ at $37^{\circ} \mathrm{C}$. Subsequently, total nitrites in the serum were assayed by adding $500 \mu 1$ of Griess reagent $(4 \%$ sulphanilamide and $0.2 \%$ naphtylendiamide in $10 \%$ phosphoric acid) to each sample (24).

End-products of lipid peroxidation. Hydroxynonenal (HNE) concentration was also determined on fresh cytosolic fractions by the Esterbauer et al method $(25,26)$. An aliquot of cytosol $(200 \mu \mathrm{l})$ was extracted in an equal volume of a solution of acetic acid: acetonitrile (4:96, v:v). After centrifugation at $250 \mathrm{x}$ $\mathrm{g}$ for $20 \mathrm{~min}$ at $4^{\circ} \mathrm{C}, 50 \mu \mathrm{l}$ of supernatant were injected into an HPLC Symmetry $\mathrm{C}_{18}$ column $(5 \mathrm{~mm}, 3.9 \times 150 \mathrm{~mm})$. The mobile phase used was acetonitrile:bidistilled water $(42 \%, \mathrm{v}: \mathrm{v})$. The HNE concentration was calculated by comparison with a standard solution of HNE (Calbiochem-Novabiochem Corp., La Jolla, CA, USA) of known concentration.

ROS. Reactive oxygen species (ROS) were measured using 2',7'-dichlorofluorescein diacetate (DCFH-DA) as a probe. DCFH-DA is a stable, non-fluorescent molecule that readily crosses the cell membrane and is hydrolyzed by intracellular esterases to non-fluorescent 2',7'-dichlorofluorescein (DCFH), which is rapidly oxidized in the presence of peroxides to highly fluorescent $2^{\prime}, 7^{\prime}$-dichlorofluorescein (DCF), which is then measured fluorimetrically (27).

$G S H$. Reduced glutathione (GSH) levels were evaluated as described (28). Briefly, a mixture was directly prepared in cuvette: $2.25 \mathrm{ml}$ of $0.1 \mathrm{M} \mathrm{K}$-phosphate buffer, $\mathrm{pH} 8.0 ; 0.2 \mathrm{ml}$ of the sample (plasma or PBMCs cytosol fractions) and $25 \mu 1$ of $10 \mathrm{mM}$ DTNB in methanol (Ellman's reagent). After $1 \mathrm{~min}$ the assay absorbance was measured at $412 \mathrm{~nm}$ and the GSH concentration was calculated by comparison with a standard curve.

Vitamin E. $\alpha$-tocopherol was assayed by the method described by Burton et al (29): after extraction of the sample $(0.5 \mathrm{ml}$ aliquot of plasma) with $1 \mathrm{ml} \mathrm{n}$-heptane and brief centrifugation, the heptane phase was collected for HPLC analysis. A Supercosil-LC-Si column $(25 \mathrm{~cm}$ x $4.6 \mathrm{~mm}$, Supelco Inc., PA, USA) was used, the mobile phase being n-hexane-isopropanol (99:1, v:v) and the flow rate $2.0 \mathrm{ml} /$ min; the fluorescence detector was set to $298 \mathrm{~nm}$ excitation and $325 \mathrm{~nm}$ emission.

Statistical analysis. Results are expressed throughout the text as mean $\pm 1 \mathrm{SD}$ and the significance of the difference between the mean values of patients and controls was determined with the two-tail Student's t-test. Significance was attained for $\mathrm{P}<0.05$.

\section{Results}

Evaluation of pro-inflammatory cytokines. The levels of serum TNF- $\alpha$, TNF-RI, TNF-RII and IL-6 measured in the groups of patients and controls are reported in Table II.

Serum TNF- $\alpha$ was significantly increased in both groups of neoplastic patients, both cachectic and non-cachectic, in comparison with control subjects. Moreover, TNF- $\alpha$ was significantly higher in cachectic than in non-cachectic patients. As reported in Fig. 1, the behavior of TNF- $\alpha$ RNA expression in PBMC was similar. The expression of TNF- $\alpha$ gene was increased in all neoplastic patients being the highest in cachectic patients. 


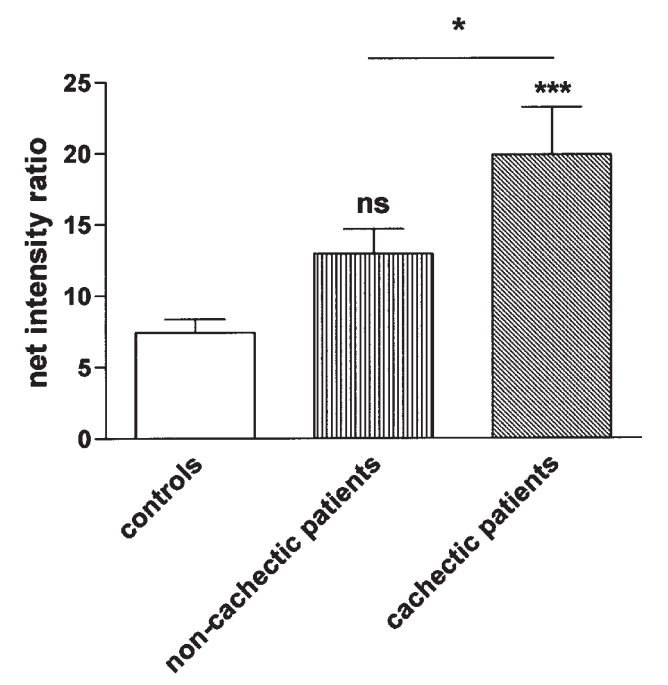

Figure 1. TNF- $\alpha$ RNA expression in patient PBMC. The expression of TNF- $\alpha$ gene in PBMC was evaluated on RNA samples obtained from PBMC of neoplastic patients (non-cachectic, $\mathrm{n}=11$ and cachectic, $\mathrm{n}=10$ ) and controls, $\mathrm{n}=14$. Results are expressed as mean $\pm \mathrm{SD}$ of net intensity of bands analysed with the PC program Kodak 1D Image System and normalized for the intensity of the corresponding $B$-actin band. Not significant, ns; $* \mathrm{P}<0.05$, $* * * \mathrm{P}<0.001$.

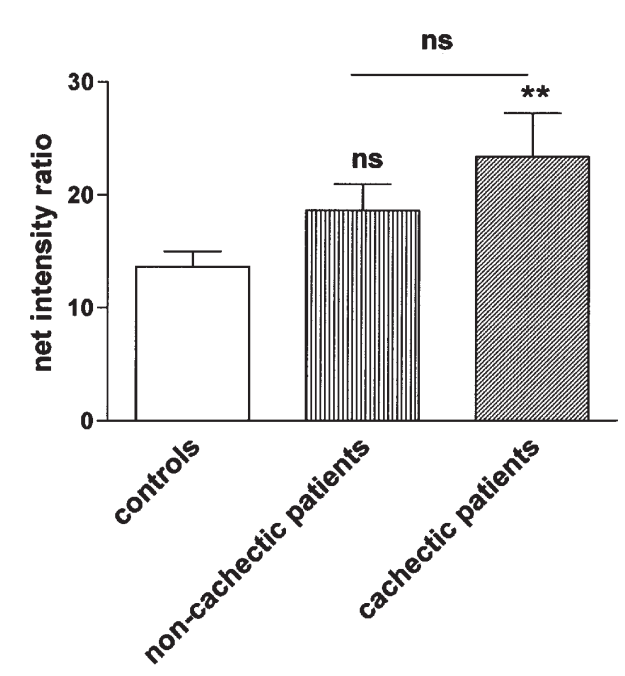

Figure 2. TNFR-I RNA expression in patient PBMC. The expression of TNFR-I gene in PBMC was evaluated on RNA samples obtained from PBMC of neoplastic patients (non-cachectic, $n=12$ and cachectic, $n=12$ ) and controls, $\mathrm{n}=19$. Results are expressed as mean $\pm \mathrm{SD}$ of net intensity of bands analysed with the PC program Kodak 1D Image System and normalized for the intensity of the corresponding $B$-actin band. Not significant, ns; $* * \mathrm{P}<0.005$.

Serum soluble TNF-RI was also increased in both neoplastic patient groups, but no significant difference was observed between cachectic and non-cachectic patients. Similarly, TNF-RI RNA expression in PBMC (Fig. 2) was increased in patient groups in comparison with controls, without any difference between cachectic and non-cachectic patients.

Furthermore, serum soluble TNF-RII was increased in both neoplastic patient groups, but no significant difference was observed between cachectic and non-cachectic patients. TNF-RII RNA expression in PBMC (Fig. 3) was also

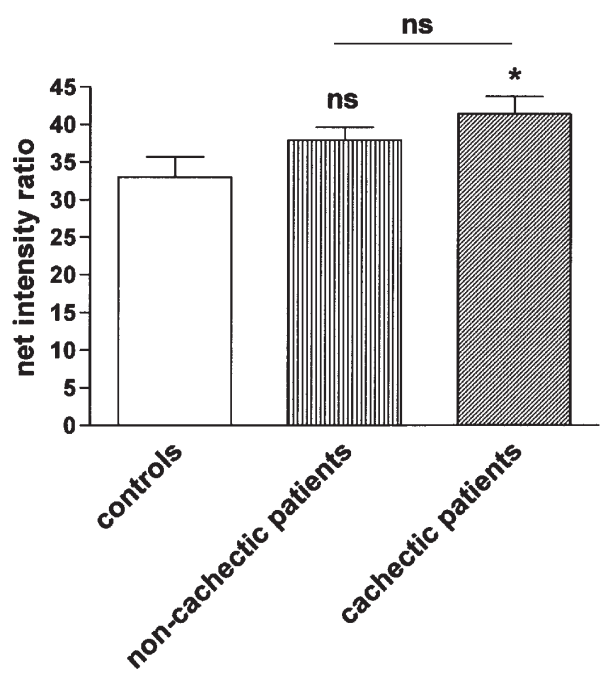

Figure 3. TNFR-II RNA expression in patient PBMC. The expression of TNFR-II gene in PBMC was evaluated on RNA samples obtained from PBMC of neoplastic patients (non-cachectic, $n=10$ and cachectic, $n=10$ ) and controls, $n=15$. Results are expressed as mean \pm SD of net intensity of bands analysed with the PC program Kodak 1D Image System and normalized for the intensity of the corresponding $\beta$-actin band. Not significant, ns; $* \mathrm{P}<0.05$.

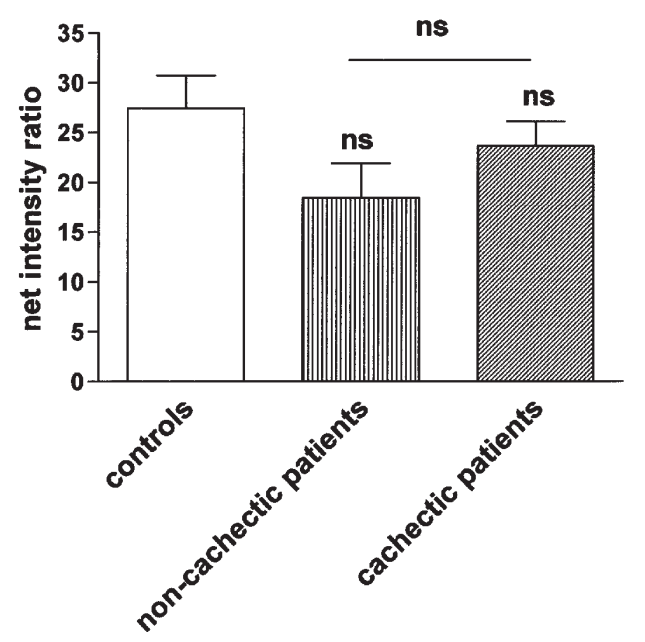

Figure 4. IL-6 RNA expression in patient PBMC. The expression of IL-6 gene in PBMC was evaluated on RNA samples obtained from PBMC of neoplastic patients (non-cachectic, $n=10$ and cachectic, $n=9$ ) and controls, $\mathrm{n}=15$. Results are expressed as mean $\pm \mathrm{SD}$ of net intensity of bands analysed with the PC program Kodak 1D Image System and normalized for the intensity of the corresponding B-actin band. Not significant, ns.

increased in patient groups, without any difference between cachectic and non-cachectic patients.

Finally, serum IL-6 level was significantly higher in both neoplastic patient groups in comparison with controls, being however similar in cachectic and non-cachectic subjects. On the contrary, the level of IL-6R RNA expression in PBMC, (Fig. 4), showed no difference among neoplastic patients, cachectic or not and control subjects. No difference was observed among the three groups as far as IL-6R RNA expression in PBMC was concerned (Fig. 5).

Evaluation of oxidative stress and anti-oxidant parameters. The levels of oxidative and anti-oxidant parameters are 
Table III. Serum concentration of oxidative stress and anti-oxidant parameters in lung cancer patients.

\begin{tabular}{|c|c|c|c|c|}
\hline & $\begin{array}{l}\text { Controls } \\
\text { (ctrl) }\end{array}$ & $\begin{array}{l}\text { Non-cachectic } \\
\text { patients (nc) }\end{array}$ & $\begin{array}{c}\text { Cachectic } \\
\text { patients (c) }\end{array}$ & \\
\hline $\mathrm{HNE}(\mu \mathrm{M})$ & $2.97 \pm 0.56(n=12)$ & $4.59 \pm 0.48(n=15)$ & $4.02 \pm 0.39(n=13)$ & $\begin{array}{l}\text { ctrl vs nc, } \mathrm{P}<0.05 \\
\text { ctrl vs } \mathrm{c}, \mathrm{P}<0.001 \\
\text { nc vs } \mathrm{c}, \mathrm{ns}\end{array}$ \\
\hline ROS (UF/ml) & $111.9 \pm 5.2(n=14)$ & $138.9 \pm 16(n=15)$ & $143.8 \pm 21(n=14)$ & $\begin{array}{l}\text { ctrl vs nc, } \mathrm{P}<0.05 \\
\text { ctrl vs } \mathrm{c}, \mathrm{P}<0.001 \\
\text { nc vs } \mathrm{c}, \mathrm{P}<0.01\end{array}$ \\
\hline $\mathrm{NO}_{2} / \mathrm{NO}_{3}(\mu \mathrm{M})$ & $16.8 \pm 1.13(\mathrm{n}=10)$ & $35.5 \pm 2.35(n=13)$ & $26.4 \pm 1.73(n=11)$ & $\begin{array}{l}\text { ctrl vs nc, } \mathrm{P}<0.05 \\
\text { ctrl vs } \mathrm{c}, \mathrm{P}<0.001 \\
\text { nc vs } \mathrm{c}, \mathrm{P}<0.01\end{array}$ \\
\hline $\mathrm{GSH}(\mu \mathrm{g} / \mathrm{ml})$ & $75.3 \pm 6.72(n=12)$ & $67.9 \pm 7.53(n=16)$ & $61.9 \pm 5.71(n=12)$ & $\begin{array}{l}\text { ntrl vs nc, } \mathrm{P}<0.05 \\
\text { ctlr vs } \mathrm{c}, \mathrm{P}<0.001 \\
\text { nc vs } \mathrm{c}, \mathrm{P}<0.01\end{array}$ \\
\hline Vitamin $\mathrm{E}(\mu \mathrm{M})$ & $126.2 \pm 8.5(n=14)$ & $84.9 \pm 10.9(n=13)$ & $73.4 \pm 5.8(n=12)$ & $\begin{array}{l}\text { ntrl vs nc, } \mathrm{P}<0.05 \\
\text { ctlr vs } \mathrm{c}, \mathrm{P}<0.001 \\
\text { nc vs } \mathrm{c}, \mathrm{P}<0.01\end{array}$ \\
\hline
\end{tabular}

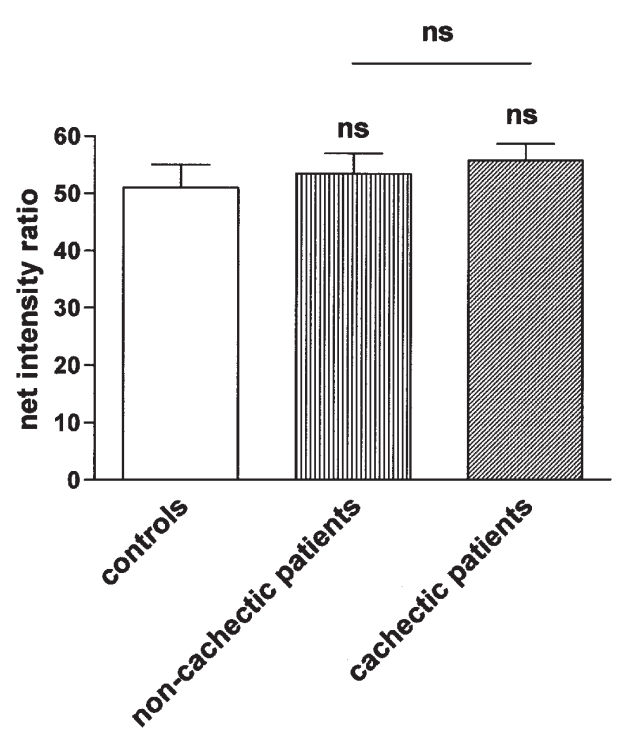

Figure 5. IL-6R RNA expression in patient PBMC. The expression of IL-6R gene in PBMC was evaluated on RNA samples obtained from PBMC of neoplastic patients (non-cachectic, $n=12$ and cachectic, $n=10$ ) and controls, $\mathrm{n}=16$. Results are expressed as mean $\pm \mathrm{SD}$ of net intensity of bands analysed with the PC program Kodak 1D Image System and normalized for the intensity of the corresponding $\beta$-actin band. Not significant, ns.

reported in Table III. In both groups of neoplastic patients the levels of $\mathrm{HNE}$, ROS and the $\mathrm{NO}_{2} / \mathrm{NO}_{3}$ ratio were significantly higher than in the controls, while GSH and vitamin E were significantly reduced. The increase of ROS as well as the reduction of vitamin $\mathrm{E}$ were more pronounced in cachectic than in non-cachectic patients.

\section{Discussion}

The present study reports the behavior of several biochemical parameters, such as proinflammatory cytokines, oxidative stress and antioxidant markers, in lung cancer patients and try to delineate a bio-humoral profile able to identify the very first development of cancer-related cachexia. We observe here that cachectic patients present higher serum levels of TNF- $\alpha$, ROS, higher PBMC expression of TNF- $\alpha$ gene and lower serum GSH and vitamin E levels.

Cachexia is generally defined as the loss of $>5 \%$ of an individual's baseline body weight over 2 to 6 months $(30,31)$. Nevertheless, several authors reported that the choice of weight loss $>10 \%$ of the body weight is a better cut-off point to distinguish cachectic from non-cachectic patients $(17,32)$. In the present study we decided to identify our cachectic patients using the loss of $>5 \%$ of body weight in the last 6 months, since we wanted to identify patients in the early stages of cachexia in order to recognize any early biochemical change.

All our cancer patients presented a significant increase in serum TNF- $\alpha$, TNF-RI and TNF-RII levels. Higher TNF- $\alpha$ serum level has been reported in patients with advanced stage cancer $(16,20,21)$ and a decrease in TNF- $\alpha$ level has been described after combined cachexia treatment (33). In NSCLC patients, TNF- $\alpha$ serum level was increased with respect to controls but no difference was reported between cachectic and non-cachectic patients (17). Reports about soluble TNF receptor determination in serum from cancer patients are few and not definitive. In general, the level of both soluble receptors is increased in neoplastic and cachetic patients regardless of tumour site (34,35-37). In addition, in experimental models of cancer-related cachexia the upregulation of TNF-RI expression in muscle was reported as a putative pathogenetic mechanism $(22,38)$. We report for the first time in lung cancer patients that both soluble TNF receptors and TNF- $\alpha$ serum levels are significantly increased; furthermore, we also demonstrated that the gene expression of the three molecules in host PBMC is significantly higher than in the controls. It is therefore conceivable that serum TNF- $\alpha$ and its receptors are mainly coming from host production and they reflect the chronic inflammation status occurring in advanced cancer. However, serum levels of both receptors is not different in cachectic with respect to noncachectic patients; their expression level in PBMC is also 
similar in both groups of cancer patients. On the contrary, TNF- $\alpha$ serum level as well as PBMC gene expression is significantly more increased in cachectic patients confirming that its determination is a good marker for cachexia even in the early stages.

Serum IL-6 level was increased in all our cancer patients, but we did not observe any difference between the cachectic and non-cachectic group. The increase in serum IL-6 was previously reported in advanced cancer patients $(20,21)$ as well as in terminally ill patients about one week before death (39) and was also related to the tumour size (34). Furthermore, treatment of cachectic patients with progestagen, idomethacin and anti-cyclooxygenase- 2 determined a significant reduction of IL-6 level $(33,40)$. Kayacan and coworkers $(17)$ confirmed the increase of serum IL-6 in NSCLC patients, but failed to observe any difference between cachectic and non-cachectic patients in accordance with our observation. The increase in serum IL-6 level is not related to an increase of host production, since no modification was observed in IL-6 and IL-6R expression in host PBMC. We therefore suggest that serum IL-6 is mainly produced by lung tumours and this is also consistent with the observation from other authors (34). In conclusion, IL-6 is not a good marker of cachexia, at least in lung cancer patients, since its serum levels are mainly determined and influenced by tumoural mass (34).

Oxidative stress has been often reported to be involved in carcinogenesis (41-43) and is thought to be responsible for the chronic inflammation status occurring in advanced cancer patients and for the up-regulation of cytokine production that is pivotal for the induction of cancer-related cachexia (5). Furthermore, the excessive production of reactive oxygen species (ROS) in tumour-bearing rats was also suggested to be associated to cachexia development (18). Actually, serum ROS levels were repeatedly reported to be significantly higher in advanced cancer patients (stage IV) and also that treatment with different antioxidants caused a sensitive reduction of their level $(20,21)$. In the present study, we assessed a more complete panel of oxidative stress and antioxidant parameters. All our cancer patients showed a significant increase of ROS, $\mathrm{HNE}$ and $\mathrm{NO}_{2} / \mathrm{NO}_{3}$ together with a reduction of both $\mathrm{GSH}$ and vitamin $\mathrm{E}$, as expected. It is noteworthy that among these parameters we observed a significant difference in cachectic with respect to non-cachectic patients in ROS level that were much higher in the cachectic group and in GSH and vitamin E resulting in a greater reduction. Our data support that oxidative stress is an early event in cancer patients and that when cachexia develops it is further exacerbated. We also suggest that the simultaneous determination of several oxidative stress and antioxidant parameters are helpful in identifying patients switching towards cachexia.

In conclusion, the simultaneous determination of ROS, GSH, vitamin E, together with TNF- $\alpha$ allowed us to identify lung cancer patients developing cancer-related cachexia and we therefore suggest that a bio-humoral profile comprising both oxidative stress/antioxidant parameters and pro-inflammatory cytokines (surely TNF- $\alpha$ ) should be used for the early diagnosis and follow-up of cancer-related cachexia. Moreover, the evaluation of gene expression in patient PBMC allows a clear and easy recognition of tumour vs host factors and is also helpful from a pathogenetic and a clinical point of view.

\section{Acknowledgements}

This study was supported by the Special Project 'Oncology', Compagnia San Paolo, Turin, by MIUR and by Regione Piemonte.

\section{References}

1. Inui A: Cancer anorexia-cachexia syndrome: current issues in research and management. CA Cancer J Clin 52: 72-91, 2002.

2. MacDonald N, Easson AM, Mazurak VC, Dunn GP and Baracos VE: Understanding and managing cancer cachexia. J Am Coll Surg 197: 143-161, 2003.

3. Muscaritoli M, Bossola M, Aversa Z, Bellantone R and Rossi Fanelli F: Prevention and treatment of cancer cachexia: new insights into an old problem. Eur J Cancer 42: 31-41, 2006.

4. Argilés JM, Busquets S, Garcìa-Martìnez C and Lòpez-Soriano FJ: Mediators involved in the cancer anorexia-cachexia syndrome: past, present, and future. Nutrition 21: 977-985, 2005.

5. Argilés JM, Busquets S and Lòpez-Soriano FJ: The pivotal role of cytokines in muscle wasting during cancer. Int J Biochem Cell Biol 37: 2036-2046, 2005.

6. Tisdale MJ: Molecular pathways leading to cancer cachexia. Physiol 20: 340-348, 2005.

7. Rossi Fanelli F, Cangiano C, Muscaritoli M, Conversano L, Torelli GF and Cascino A: Tumour-induced changes in host metabolism: a posible marker of neoplatic disease. Nutrition 11: 595-600, 1995.

8. Bossola M, Muscaritoli M, Costelli P, Grieco G, Bonelli G, Pacelli F, Rossi Fanelli F, Doglietto GB and Baccino FM: Increased muscle proteasome activity correlates with disease severità in gastric cancer patients. Ann Surg 237: 384-389, 2003.

9. Savarese DM, Hsieh C and Stewart FM: Clinical impact of chemotherapy dose escalation in patients with hematologic malignancies and solid tumours. J Clin Oncol 15: 2981-2995, 1997.

10. Deans C and Wigmore SJ: Systemic inflammation, cachexia and prognosis in patients with cancer. Curr Opin Clin Nutr Metab Care 8: 265-269, 2005.

11. Macri A, Versaci A, Loddo S, Scuderi G, Travagliante M, Trimarchi G, Teti D and Famulari C: Serum levels of interleukin 1beta, interleukin 8 and tumour necrosis factor alpha as markers of gastric cancer. Biomarkers 11: 184-193, 2006.

12. Pfitzenmaier J, Vessella R, Higano CS, Noteboom JL, Wallace D Jr and Corey E: Elevation of cytokine levels in cachectic patients with prostate carcinoma. Cancer 97: 1211-1216, 2003.

13. Iwase S, Murakami T, Saito Y and Nakagawa K: Steep elevation of blood interleukin-6 (IL-6) associated only with late stages of cachexia in cancer patients. Eur Cytokine Netw 15: 312-316, 2004.

14. Ebrahimi B, Tucker SL, Li D, Abbruzzese JL and Kurzrock R: Cytokines in pancreatic carcinoma: correlation with phenotypic characteristics and prognosis. Cancer 101: 2727-2736, 2004.

15. Kaminska J, Nowacki MP, Kowalska M, Rysinska A, Chwalinski M, Fuksiewicz M, Michalski W and Chechlinska M: Clinical significance of serum cytokine measurements in untreated colorectal cancer patients: soluble tumour necrosis factor receptor type I-an independent prognostic factor. Tumour Biol 26: 186-194, 2005.

16. Mantovani G, Maccio A, Melis G, Mura L, Massa E and Mudu MC: Restoration of functional defects in peripheral blood mononuclear cells isolated from cancer patients by thiol antioxidants alpha-lipoic acid and $\mathrm{N}$-acetyl cysteine. Int $\mathrm{J}$ Cancer 86: 842-847, 2000.

17. Kayacan O, Karnak D, Beder S, Gullu E, Tutkak H, Senler FC and Koksal D: Impact of TNF-alpha and IL-6 levels on development of cachexia in newly diagnosed NSCLC patients. Am J Clin Oncol 29: 328-335, 2006.

18. Barreiro E, de la Puente B, Busquets S, Lopez-Soriano FJ, Gea J and Argiles JM: Both oxidative and nitrosative stress are associated with muscle wasting in tumour-bearing rats. FEBS Lett 579: 1646-1652, 2005.

19. Busquets S, Almendro V, Barreiro E, Figueras M, Argiles JM and Lopez-Soriano FJ: Activation of UCPs gene expression in skeletal muscle can be independent on both circulating fatty acids and food intake. Involvement of ROS in a model of mouse cancer cachexia. FEBS Lett 579: 717-722, 2005. 
20. Mantovani G, Maccio A, Madeddu C, Mura L, Massa E, Gramignano G, Lusso MR, Murgia V, Camboni P and Ferreli L: Reactive oxygen species, antioxidant mechanisms and serum cytokine levels in cancer patients: impact of an antioxidant treatment. J Cell Mol Med 6: 570-582, 2002.

21. Mantovani G, Maccio A, Madeddu C, Mura L, Gramignano G, Lusso MR, Massa E, Mocci M and Serpe R: Antioxidant agents are effective in inducing lymphocyte progression through cell cycle in advanced cancer patients: assessment of the most important laboratory indexes of cachexia and oxidative stress. J Mol Med 81: 664-673, 2003.

22. Catalano MG, Fortunati N, Arena K, Costelli P, Aragno M, Danni O and Boccuzzi G: Selective up-regulation of tumour necrosis factor receptor I in tumour-bearing rats with cancerrelated cachexia. Int J Oncol 23: 429-436, 2003.

23. Chomczynski P and Sacchi N: Single-step method of RNA isolation by acid guanidinium thiocyanate-phenol-chloroform extraction. Anal Biochem 162: 156-159, 1987.

24. Moshage H, Kok B, Huizenga JR and Jansen PL: Nitrite and nitrate determinations in plasma: a critical evaluation. Clin Chem 41: 892-896, 1995.

25. Esterbauer H, Koller E, Slee RG and Koster JF: Possible involvement of the lipid-peroxidation product 4-hydroxynonenal in the formation of fluorescent chromolipids. Biochem J 239: 405-409, 1986.

26. Esterbauer H, Schaur RJ and Zollner H: Chemistry and biochemistry of 4-hydroxynonenal, malonaldehyde and related aldehydes. Free Radic Biol Med 11: 81-128, 1991.

27. Ravindranath V: Animal models and molecular markers for cerebral ischemia-reperfusion injury in brain. Methods Enzymol 233: 610-619, 1994.

28. Owens CW and Belcher RV: A colorimetric micro-method for the determination of glutathione. Biochem J 94: 705-711, 1965.

29. Burton GW, Webb A and Ingold KU. A mild, rapid, and efficient method of lipid extraction for use in determining vitamin E/lipid ratios. Lipids 20: 29-39, 1985.

30. Fernia RA and Goyette R: The science of megestrol acetate delivery: potential to improve outcomes in cachexia. BioDrugs 19: 179-187, 2005.

31. May PE, Barber A, D'Olimpio JT, Hourihane A and Abumrad NN: Reversal of cancer related wasting using oral supplementation with a combination of beta-hydroxy-beta-methylbutyrate, arginine and glutamine. Am J Surg 183: 471-479, 2002.

32. Bing C, Russel ST, Beckett EE, Collins P, Taylor S, Barraclough R, Tisdale MJ and Wlliams G: Expression of uncoupling proteins $-1,-2$ and -3 mRNA is induced by an adenocarcinoma-derived-lipid-mobilizing factor. Br J Cancer 86: 612-618, 2002.
33. Mantovani G, Maccio A, Madeddu C, Gramignao G, Lusso MR, Serpe R, Massa E, Astara G and Deiana L: A phase II study with antioxidants, both in the diet and supplemented, pharmaconutritional support, pogestagen, and anti-cyclooxygenase- 2 showing efficacy and safety in patients with cancer-related anorexia/cachexia and oxidative stress. Cancer Epidemiol Biomarkers Prev 15: 1030-1034, 2006.

34. Kaminska J, Kowalska M, Kotowicz B, Fuksiewicz M, Glogowski M, Wojcik E, Chechlinska M and Steffen J: Preteratment serum levels of cytokines and cytokine receptors in patients with non-small cell lung cancer, and correlation with clinicopathological features and prognosis. M-CSF- an independent prognostic factor. Oncology 70: 115-125, 2006.

35. Aleman MR, Santolaria F, Batista N, de La Vega M, GonzalezReimers E, Milena A, Llanos M and Gomez-Sirvent JL: Leptin role in advanced lung cancer. A mediator of the acute phase response or a marker of the status of nutrition? Cytokine 19: 2126, 2002 .

36. Barber MD, Fearon KC and Ross JA: Relationship of serum levels of interleukin- 6 , soluble interleukin- 6 receptor and tumour necrosis factor receptors to the acute-phase protein response in advanced pancreatic cancer. Clin Sci 99: 83-87,1999.

37. Shibata M, Takekawa M and Amano S: Increased serum concentrations of soluble tumour necrosis factor receptor I in noncachectic and cachectic patients with advanced gastric and colorectal cancer. Surg Today 28: 884-888, 1998

38. Figueras M, Busquets S, Carbo N, Almendro V, Argiles JM and Lopez-Soriano FJ: Cancer cachexia results in an increase in TNFalpha receptor gene expression in both skeletal muscle and adipose tissue. Int J Oncol 27: 855-860, 2005.

39. Iwase S, Murakami T, Saito Y and Nakagawa K: Sleep elevation of blood interleukin-6 (IL-6) associated only with late stages of cachexia in cancer patients. Eur Cytokine Netw 15: 312-318, 2004.

40. Diament MJ, Peluffo GD, Stillitani I, Cerchietti LC, Navigante A, Ranuncolo SM and Klein SM: Inhibition of tumour progression and paraneoplastic syndrome development in a murine lung adenocarcinoma by medroxyprogesterone acetate and indomethacin. Cancer Invest 24: 126-131, 2006.

41. Valko M, Rhodes CJ, Moncol J, Izakovic M and Mazur M: Free radicals, metals and antioxidants in oxidative stress-induced cancer. Chem Biol Interact 160: 1-40, 2006.

42. Engel RH and Evens AM: Oxidative stress and apoptosis: a new treatment paradigm in cancer. Front Biosci 11: 300-312, 2006.

43. Klaunig JE and Kamendulis LM: The role of oxidative stress in carcinogenesis. Annu Rev Pharmacol Toxicol 44: 239-267, 2004. 